\title{
Marie-Ange Rauch, Le Théatre en France en 1968. Crise d'une histoire, histoire d'une crise
}

\section{Paola Perazzolo}

\section{(2) OpenEdition}

1 Journals

\section{Edizione digitale}

URL: http://journals.openedition.org/studifrancesi/7021

DOI: 10.4000/studifrancesi.7021

ISSN: 2421-5856

\section{Editore}

Rosenberg \& Sellier

\section{Edizione cartacea}

Data di pubblicazione: 1 septembre 2010

Paginazione: 404

ISSN: 0039-2944

\section{Notizia bibliografica digitale}

Paola Perazzolo, «Marie-Ange Rauch, Le Théatre en France en 1968. Crise d'une histoire, histoire d'une crise», Studi Francesi [Online], 161 (LIV | II) | 2010, online dal 30 novembre 2015, consultato il 09 janvier 2021. URL: http://journals.openedition.org/studifrancesi/7021 ; DOI: https://doi.org/10.4000/

studifrancesi.7021

Questo documento è stato generato automaticamente il 9 janvier 2021.

\section{(c) $(1) \odot$}

Studi Francesi è distribuita con Licenza Creative Commons Attribuzione - Non commerciale - Non opere derivate 4.0 Internazionale. 


\title{
Marie-Ange Rauch, Le Théatre en France en 1968. Crise d'une histoire, histoire d'une crise
}

\author{
Paola Perazzolo
}

\section{NOTIZIA}

MARIE-ANGE RAUCH, Le Théatre en France en 1968. Crise d'une histoire, histoire d'une crise, Paris, Éditions de l'Amandier, 2008, pp. 562.

1 Il volume in questione costituisce la terza parte di un trittico sulla storia delle politiche teatrali nel xx secolo. Interessatasi dapprima all'azione del ministero Malraux e successivamente alla storia sociale e sindacale degli artisti interpreti dal 1917 al 1960, Marie-Ange Rauch prende ora in considerazione la rottura sociale, politica e culturale della Rivoluzione di maggio inserendola all'interno dell'evoluzione dell'arte e delle politiche teatrali del decennio. Per meglio contestualizzare gli avvenimenti, l'A. traccia il panorama dell'epoca da diversi punti di vista, presentando nel primo capitolo le «réussites et contradictions» del processo di decentralizzazione in atto dall'inizio del secolo oltre che le linee guida, i successi e le difficoltà della politica culturale francese tra il 1959, data della creazione del Ministero degli Affari Culturali, e il 1968, data della virulenta messa in discussione della suddetta politica. Segue un capitolo in cui viene rievocata l'evoluzione in atto fin dall'inizio di una decade segnata da un mal de vivre che la nuova generazione tenta di esorcizzare attraverso una «rage de vivre» (Le Goff) che si vuole antitetica rispetto ai valori e ai costumi della "società dello spettacolo". L'insoddisfazione sociale e politica - quest'ultima legata al processo di decolonizzazione e alla forte instabilità mondiale - inducono organizzazioni e associazioni studentesche ad una maggiore politicizzazione e ad un maggiore impegno sociale e culturale. Aspetti, questi, che si concretizzano anche attraverso lo sviluppo di un teatro universitario di ricerca, molto influenzato da esperienze e sperimentazioni straniere (Bread and 
Puppets, Living Theatre, Teatro Laboratorio di Grotowski, i quali trovano una vetrina appropriata ed efficace nel neonato Festival di Nancy) che portano alla messa in discussione non solo della tradizione teatrale, ma anche del concetto di cultura e di performance. I successivi quattro capitoli rievocano sviluppi, cause e conseguenze degli avvenimenti più (l'occupazione del teatro dell'odéon, la dichiarazione di Villeurbanne, la contestazione del festival di Avignone) o meno noti del 1968, al fine di presentare i mesi della contestazione prendendo in considerazione anche la posizione delle istituzioni ufficiali e dei diversi professionisti dello spettacolo tra cui creatori, tecnici, direttori di teatri nazionali - il T.N.P., la Comédie-Française, il Conservatorio di Arte Drammatica - o di periferia, componenti delle troupes che tentano la ricerca del cosiddetto non-public. Nell'ultimo capitolo l'A. evoca le conseguenze principali di questa deflagrazione su un ambiente teatrale traumatizzato e disilluso, caratterizzato da un ripiegamento conservatore e dalla ridefinizione di una politica culturale le cui debolezze sono apparse in tutta la loro evidenza. Terminano il volume due annessi molto utili: una tavola cronologica e il testo della dichiarazione di Villeurbanne.

2 Con questo lavoro interessante e molto ben documentato, Marie-Ange Rauch traccia in modo particolareggiato il panorama di un periodo convulso e importante per l'evoluzione delle pratiche e delle politiche teatrali francesi, inserendo la sua analisi in un contesto ampio a livello cronologico e sociale ed evidenziando come alcune delle problematiche sollevate in quegli anni non siano affatto superate o risolte ma continuino a sottendere le riflessioni di artisti e istituzioni. 